\title{
Endovascular stents in children under 1 year of age: acute impact and late results
}

\author{
Yoshiho Hatai, David G Nykanen, William G Williams, Robert M Freedom, \\ Lee N Benson
}

\begin{abstract}
Objectives-To review efficacy and safety of endovascular stent implants in children $<1$ year of age with congenital heart lesions.

Design-Retrospective study of patients in a tertiary care setting.

Patients-26 children (median age of $4 \cdot 7$ months, range 2 days to 1 year) with various vascular obstructive lesions.

Intervention-Percutaneous or intraoperative implantation of balloon expandable endovascular stents.

Results-Optimal stent placement was obtained in 31 of the 37 deployed implants. Complications resulted primarily from stent malpositioning and one episode of bleeding at a puncture site. Stent implantation in three patients with a restrictive arterial duct allowed for patency and five patients with conduit stenosis had mean (SD) right ventricule to systemic artery pressure ratios falling from $0.99(0.20)$ to $0.52(0.18)(P<0.05)$. In 10 patients with pulmonary artery stenosis, the mean vessel diameter increased from $2.8(0.9) \mathrm{mm}$ to $5.8(1.4)$ $\mathrm{mm}(P \ll 0.001)$. No clinical improvement was seen in two patients because of diffuse hypoplasia of the pulmonary vessels. Nine of 10 patients with miscellaneous obstructive lesions improved clinically. Recatheterisation was performed in 19 patients (median 8 months, range 12 days to 28 months) and 11 patients required redilatation (17 stents). Conclusions-Stent implantation is technically feasible in infants and under specific circumstances may provide an alternative to surgical palliation or avoid reoperation. The long term impact on clinical course, however, involves further interventions directed at stent management.
\end{abstract}

(Br Heart f 1995;74:689-695)

Keywords: endovascular stent; balloon dilatation; infants; short term results; long term results

Endovascular stent implants have been used in various obstructive lesions in childhood, including peripheral pulmonary artery steno- sis, systemic or pulmonary venous obstructions, postoperative conduit stenosis, the restrictive arterial duct, and coarctation of the aorta. ${ }^{1-3}$ The effectiveness of such endovascular implants in management of congenital heart lesions has generally been satisfactory and intermediate follow up has been promising, although restenosis has been encountered. ${ }^{34}$ However, most studies have addressed applications in older children. In this regard, infants not infrequently require surgical reintervention or therapeutic catheterisation to address complex cardiac lesions. Because the vessels are smaller, there have been concerns that stent placement in younger children may be difficult, and more complications may occur than noted in older populations. To this end, no studies have specifically addressed whether stent implants can be used safely and effectively, or can improve patient management, in patients of less than 1 year of age.

The purpose of this study was: (1) to evaluate the feasibility, safety, and clinical impact of stent implantation in children $<1$ year of age, and (2) to assess the possibility of stent redilatation within the growing patient.

\section{Methods}

PATIENTS

Between November 1989 and April 1994, 26 patients $<1$ year of age had endovascular stent implantation at the Hospital for Sick Children, Toronto. Parental informed consent was obtained in each patient. There were 11 males and 15 females (median age $4 \cdot 7$ months, range 2 days to 1 year, including seven neonates and median weight $5.3 \mathrm{~kg}$, range $2 \cdot 2$ to $9.5 \mathrm{~kg}$ ). Twenty patients had undergone previous surgery (median 4.0 months, range 1 day to 11 months) between surgery and stent implantation. Cardiac diagnoses of congenital heart disease are listed in table 1 .

Table 1 Cardiac diagnosis

Truncus arteriosus

Hypoplastic left heart syndrome

Pulmonary atresia

Tricuspid atresia with pulmonary atresia

Ventricular septal defect

Transposition of the great arteries

Anomalous pulmonary venous drainage

Double inlet left ventricle

Isolated right pulmonary artery from a right ductus arteriosus

Tetralogy of Fallot 
Patients were considered for stent implantation if they had obstructive lesions that resulted in symptoms or haemodynamic deterioration without significant improvement after attempted balloon dilatation, where appropriate. For this review, patients were retrospectively divided into four general categories: (1) resrictive arterial duct with duct dependent pulmonary or systemic blood flows; (2) right ventricular to pulmonary artery conduit stenosis; (3) congenital or acquired pulmonary artery stenosis; and (4) miscellaneous lesions including stenosis in aortopulmonary or bidirectional cavopulmonary shunts and stenotic systemic or pulmonary veins. One patient was classified into both groups 3 and 4 .

STENT PLACEMENT

A Palmaz or Palmaz-Schatz stent (Johnson and Johnson Interventional Systems) was used exclusively in all patients. Three sizes of stents were deployed and selected according to the stenotic diameters, to provide a uniform calibre for the vessel without overdistending the vessel wall. Sizes included: (1) 30 mm length, $3.4 \mathrm{~mm}$ in diameter ("iliac stent") ( $\mathrm{n}=1)$; (2) $20,15,12 \mathrm{~mm}$ length by $1.8 \mathrm{~mm}$ ( $\mathrm{n}=24$ ); and (3) $15 \mathrm{~mm}$ by $1.8 \mathrm{~mm}$ ("coronary stent") $(n=12)$. Stent placement was performed percutaneously in the catheterisation laboratory whenever possible. Pressure measurements and angiograms were performed before and immediately after implantation. Angiographic measurements were corrected for magnification by the known catheter diameters.

The method of stent placement has been described previously, ${ }^{25}$ and all procedures were performed under general anaesthesia. Heparin sulphate $(150 \mathrm{IU} / \mathrm{kg})$ was given at the beginning of the procedure and additional doses given to maintain the activated clotting time at $>250 \mathrm{~s}$. Stents were mounted by hand on balloon angioplasty catheters, diameters chosen as noted above. The stent-catheter complex was advanced through a long sheath (Cook) previously placed across the target site, over a Teflon coated 0.035 inch $(0.89$ $\mathrm{mm})$ regular or extra-stiff interventional guidewire (Amplatz type, Cook). More recently, however, the stent-balloon complex was inserted into a long sheath and manoeuvred as a single unit together percutaneously over the guidewire to the target site. This approach avoided stent slippage from the balloon while traversing acute turns such as the right ventricular-infundibular corner. Occasionally, the stent-balloon-sheath was gently curved by $10^{\circ}$ before percutaneous entry to facilitate this manoeuvre. When coronary stents were used, a premounted sheathcovered stent system was positioned over a 0.014 inch guidewire. To facilitate positioning in small children, a stiff firm guidewire was important. For the coronary stents, the floppy end of the coronary guidewire was cut off within $1 \mathrm{~cm}$ of the stiffer portion and positioned through a catheter across the lesion. After implantation, patients were maintained on intravenous heparin sulphate $(10 \mathrm{IU} / \mathrm{kg} / \mathrm{d}$ ) for $24 \mathrm{~h}$, then began on acetylsalicylic acid $(3-5 \mathrm{mg} / \mathrm{kg} / \mathrm{d}$ ) or warfarin (INR, $2-2 \cdot 5)$, or both, for 6 to 12 months.

\section{DEFINITIONS}

Placement was considered successful when the stent was appropriately positioned and expanded at the target site. Implantation was clinically successful if there was a period of improvement when the following conditions were met: (1) disappearance or improvement in symptoms; (2) avoiding or postponing surgical repair; (3) making inoperable circumstances, operable. Haemodynamic or angiographic success was arbitrarily defined as an increase in pulmonary artery size of $50 \%$ or more in diameter, or a $20 \%$ decrease in right ventricle to systemic artery peak systolic pressure ratio. ${ }^{67}$ In the situation of conduit stenosis, success was defined when this ratio was reduced to $<50 \%$. Angiographic assessment at follow up catheterisation of intimal proliferation (growth within the stent lumen) was graded as none, mild, moderate, or severe.

\section{STATISTICAL ANALYSIS}

Normally distributed values are expressed as mean (SD). A paired, two tailed $t$ test was used to compare measurements before and after procedure. A P value $<0.05$ was considered statistically significant.

\section{Results \\ OUTCOMES}

Clinical profiles of the patients are presented in table 2. A balloon angioplasty before stent implantation was performed in 16 patients (19 procedures) using low pressure balloons (tolerant to 8 atmospheres). In 21 patients (84\%), a stent was placed percutaneously, while in five patients (10 stents) an intraoperative approach was used. Vascular access was obtained through the internal jugular vein in five patients, the remainder through the femoral vessels. Catheterisation time ranged from 55 to $210 \mathrm{~min}$ and mean fluoroscopy time was 36 (range 11 to 86 ) minutes.

Placement success was attained in 31 of the 37 deployed stents (84\%). Of these deployed stents, a single implant was performed in 19 patients, two implants in four, three implants in two, and four stents in one. In 21 patients $(81 \%)$, stent implantation resulted in an improved clinical course: nine patients (43\%) had symptomatic improvement, nine (43\%) avoided or delayed surgical intervention, and three $(14 \%)$ went on to total correction. Among patient categories, clinical success rate of the procedures was $67 \%$ in the restrictive arterial duct, $60 \%$ in conduit stenosis, $60 \%$ in pulmonary artery stenosis, and $80 \%$ in miscellaneous stenotic vessels.

\section{SPECIFIC LESIONS}

\section{The arterial duct}

Three patients with ductal dependent pulmonary $(n=1)$ or systemic $(n=2)$ blood flows had implants to prevent ductal closure. 
Table 2 Clinical profiles and results of stent implantation

\begin{tabular}{|c|c|c|c|c|c|c|c|c|c|c|}
\hline \multirow[b]{2}{*}{ Patients } & \multirow{2}{*}{$\begin{array}{l}\text { Age } \\
\text { at implants }\end{array}$} & \multirow{2}{*}{$\begin{array}{l}\text { Weight } \\
(\mathrm{kg})\end{array}$} & \multirow[b]{2}{*}{ Location } & \multirow{2}{*}{$\begin{array}{l}\text { Stent length- } \\
\text { balloon size } \\
(\mathrm{mm})\end{array}$} & \multirow[b]{2}{*}{ Complication } & \multirow[b]{2}{*}{ Clinical features } & \multicolumn{2}{|c|}{ Outcome } & \multirow{2}{*}{$\begin{array}{l}\text { Follow } \\
\text { up }\end{array}$} & \multirow[b]{2}{*}{ Redilatation } \\
\hline & & & & & & & success & Final & & \\
\hline 1 & $2 \cdot 0 \mathrm{~d}$ & $3 \cdot 0$ & Duct & $20-5$ & & Progressive cyanosis & Yes & Died & $24 \mathrm{~d}$ & \\
\hline 2 & $2.9 \mathrm{~m}$ & $3 \cdot 6$ & Duct & $20-6$ & & Progressive cyanosis & No & Died & & \\
\hline 3 & $3 \cdot 2 \mathrm{~m}$ & $5 \cdot 0$ & Duct & $15-4$ & & Respirator dependent & Yes & Died & & \\
\hline 4 & $3.2 \mathrm{~m}$ & $6 \cdot 5$ & Conduit & $20-8$ & & Asymptomatic, RV/SA $=0.93$ & No & $\mathrm{RV} / \mathrm{SA}=0.77$ & $12 \mathrm{~m}$ & Yes \\
\hline 5 & $5.5 \mathrm{~m}$ & $6 \cdot 5$ & Conduit & $20-8$ & & Asymptomatic, RV/SA $=0.98$ & Yes & $\mathrm{RV} / \mathrm{SA}=0.53$ & $8 \mathrm{~m}$ & Yes \\
\hline 6 & $6.8 \mathrm{~m}$ & $7 \cdot 4$ & Conduit & $20-8,10$ & Yes & Asymptomatic, RV/SA $=1.02$ & No & Reoperation & & \\
\hline 7 & $10.6 \mathrm{~m}$ & $9 \cdot 4$ & Conduit & $20-10$ & & Asymptomatic, RV/SA $=1.0$ & Yes & $\mathrm{RV} / \mathrm{SA}=0.35$ & $19 \mathrm{~m}$ & Yes \\
\hline 8 & $11.6 \mathrm{~m}$ & $9 \cdot 5$ & Conduit & $15-6$ & & Asymptomatic, stenosis & Yes & Improved & $35 \mathrm{~m}$ & Yes \\
\hline 9 & $9 \cdot 0 \mathrm{~d}$ & $3 \cdot 4$ & $\mathrm{LPA}^{\star}$ & $15-4$ & & Cyanosis & No & Removed & $15 \mathrm{~m}$ & Yes \\
\hline \multirow{4}{*}{11} & $12 \cdot 0 \mathrm{~d}$ & $2 \cdot 6$ & LPA & $15-4$ & Yes & Cyanosis, PGE dependent & No & Removed & & \\
\hline & $27 \cdot 0 \mathrm{~d}$ & $3 \cdot 3$ & LPA & $15-4$ & Yes & Oxygen dependent & No & Removed & & \\
\hline & $2.9 \mathrm{~m}$ & 3.9 & $\mathrm{LPA}^{\star}$ & $15-4$ & & Cyanosis & Yes & To repair & $10 \mathrm{~m}$ & \\
\hline & $12.0 \mathrm{~m}$ & $6 \cdot 5$ & $\mathrm{LPA}^{\star}$ & $15-4$ & & Low cardiac output & No & Died & & Yes \\
\hline \multirow[t]{2}{*}{12} & $1.2 \mathrm{~m}$ & $2 \cdot 6$ & LPA & $15-4$ & & Severe RV dysfunction & No & Removed & & \\
\hline & $1.9 \mathrm{~m}$ & $2 \cdot 4$ & $\mathrm{LPA}^{\star} \mathrm{RPA}^{\star}$ & $20-6$ & & Respirator dependent & Yes & Discharged & $2 \mathrm{~m}$ & \\
\hline \multirow[t]{2}{*}{13} & $1.8 \mathrm{~m}$ & $3 \cdot 1$ & LPA & $15-4$ & & Respirator dependent & Yes & Discharged & $6 \mathrm{~m}$ & Yes \\
\hline & $11.8 \mathrm{~m}$ & $6 \cdot 7$ & RPA & $15-7$ & & $\mathrm{RV}$ dysfunction, RV/SA $=1 \cdot 0$ & Yes & $\mathrm{RV} / \mathrm{SA}=0.52$ & $5 \mathrm{~m}$ & \\
\hline \multirow{4}{*}{$\begin{array}{l}14 \\
15 \\
16\end{array}$} & $4.6 \mathrm{~m}$ & $5 \cdot 5$ & RPA & $15-4$ & Yes & Progressive cyanosis & Yes & To repair & $6 \mathrm{~m}$ & \\
\hline & $4.7 \mathrm{~m}$ & 4.9 & LPA RPA & $20-8$ & & $\mathrm{RV}$ dysfunction, $\mathrm{RV} / \mathrm{SA}=0.7$ & Yes & $\mathrm{RV} / \mathrm{SA}=0.36$ & $12 \mathrm{~m}$ & \\
\hline & $5 \cdot 2 \mathrm{~m}$ & $8 \cdot 0$ & LPA & $15-7$ & & Asymptomatic, stenosis & Yes & Improved & $22 \mathrm{~m}$ & Yes \\
\hline & $9 \cdot 7 \mathrm{~m}$ & $9 \cdot 0$ & $\mathrm{RPA}^{\star}$ & $30-8$ & & Persistent stenosis & No & & $17 \mathrm{~m}$ & Yes \\
\hline \multirow{9}{*}{$\begin{array}{l}17 \\
18 \\
19 \\
20 \\
21 \\
22 \\
23 \\
24\end{array}$} & $5.4 \mathrm{~m}$ & $4 \cdot 8$ & RPA & $20-8$ & & Recurrent stenosis & Yes & Improved & $17 \mathrm{~m}$ & Yes \\
\hline & $28 \cdot 0 \mathrm{~d}$ & $2 \cdot 2$ & RPV & $15-5$ & & Pulmonary congestion & Yes & Occluded & $11 \mathrm{~m}$ & \\
\hline & $14.0 \mathrm{~d}$ & $2 \cdot 2$ & RBTS & $15-4$ & Yes & Cyanosis, Sat $60 \%$ & Yes & Improved, Sat 93\% & $3 \mathrm{~m}$ & \\
\hline & $15 \cdot 0 \mathrm{~d}$ & $3 \cdot 4$ & RSCA-BTS & $15-4$ & Yes & Cyanosis & Yes & To repair & $10 \mathrm{~m}$ & \\
\hline & $12.0 \mathrm{~m}$ & $7 \cdot 4$ & RBTS & $20-6$ & & Cyanosis, Sat $65 \%$ & Yes & Improved, Sat $85 \%$ & $4 \mathrm{~m}$ & \\
\hline & $5.5 \mathrm{~m}$ & $7 \cdot 9$ & SVC & $12-10$ & & Recurrent SVC syndrom & Yes & Improved & $21 \mathrm{~m}$ & \\
\hline & $9 \cdot 4 \mathrm{~m}$ & $6 \cdot 4$ & ASD & $20-10$ & Yes & Chronic heart failure & No & Died & & \\
\hline & $2.7 \mathrm{~m}$ & $3 \cdot 5$ & LPA & $15-4$ & & Cyanosis & Yes & Improved & $4 \mathrm{~m}$ & Yes \\
\hline & $6.5 \mathrm{~m}$ & $4 \cdot 3$ & CPA & $15-8$ & & Cyanosis & Yes & Improved & $8 \mathrm{~m}$ & Yes \\
\hline \multirow{3}{*}{$\begin{array}{l}25 \\
26\end{array}$} & $10.0 \mathrm{~m}$ & $6 \cdot 9$ & CPA & $20-8$ & & SVC syndrome & Yes & Improved & $23 \mathrm{~m}$ & \\
\hline & $7.0 \mathrm{~m}$ & $5 \cdot 1$ & $\mathrm{LPV}^{\star} \mathrm{RPV}^{\star}$ & 20 & & Tachypnea & Yes & Improved & & Yes \\
\hline & $11.0 \mathrm{~m}$ & $7 \cdot 3$ & $\mathrm{RPV}^{\star}$ & $20-10$ & & Asymptomatic, PH & No & Restenosis & $36 \mathrm{~m}$ & Yes \\
\hline
\end{tabular}

ASD, atrial septal defect; CPA, cavopulmonary anastomosis; LPA, left pulmonary artery; LPV, left pulmonary vein; PH, pulmonary hypertension; PGE, prostaglandin E; PV, pulmonary vein; RBTS, right Blalock-Taussig shunt; RPA, right pulmonary artery; RPV, right pulmonary vein; RSCA, right subclavian artery; RV, right ventricle; RV/SA, right ventricle-systemic arterial pressure ratio; Sat, saturation; SVC, superior vena cava.

All patients had implants, without previous balloon angioplasty, and were successfully positioned, with ductal patency confirmed angiographically. No thrombosis occurred within the arterial duct during these procedures. One patient died postimplantation in the catheterisation laboratory after a balloon septostomy for a restrictive atrial defect which resulted in reduced systemic blood flow in the setting of hypoplastic left heart syndrome. The two remaining patients maintained ductal flow without further palliative intervention for 8 and 24 days respectively.

Conduit stenosis

Five stents were implanted in five patients (median age 6.8 months, range 3.2 to 11.6 months) with right ventricular to pulmonary artery conduit stenosis. The median age at initial surgery was seven days (range five days to 1.5 months) and the median period to stent implantation, 6.6 months (range three to 11 months). Balloon angioplasty before stenting

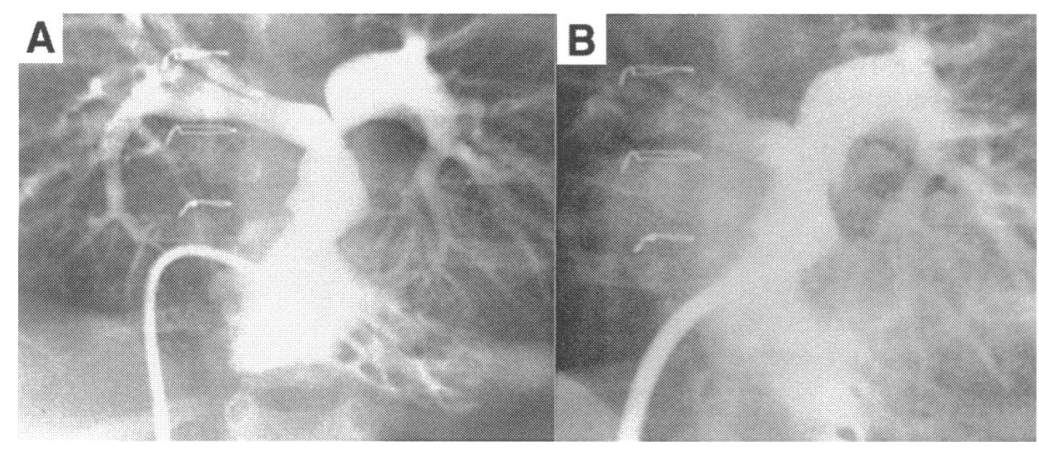

Figure 1 (A) Angiogram of patient 6 with conduit stenosis showing the distal stenosis at bifurcation of the left pulmonary artery. (B) After stent implantation, showing reduction of the right pulmonary blood flow by distorting the ostium of the right pulmonary artery. was unsuccessful. After stent implantation, haemodynamic and angiographic success was attained in four patients. The mean vessel diameter increased from 3.5 (SD $2 \cdot 0) \mathrm{mm}$ to $8.0(1.8) \mathrm{mm}(\mathrm{P}<0.05)$, peak pressure gradient across the conduit decreased from 57 (23) $\mathrm{mm} \mathrm{Hg}$ to 18 (7) $\mathrm{mm} \mathrm{Hg}(P<0.05)$, and right ventricle to systemic artery peak systolic pressure ratio fell from $0.99(0.20)$ to 0.52 $(0 \cdot 18) \quad(P<0 \cdot 05)$. Four patients avoided reoperation during follow up ranging from eight to 35 months, although one required a second stent implant nine months after the initial procedure, beyond one year of age. The remaining patient, whose deployed stent obstructed right pulmonary artery blood flow, underwent replacement of the conduit and a right pulmonary arterioplasty three days after implantation (fig 1).

\section{Pulmonary artery stenosis}

Seventeen stents were implanted in 10 patients (median age 2.9 months, range nine days to one year). There were six patients with congenital and four with acquired (postoperative) pulmonary artery stenosis. Of the 17 deployed stents, 15 were optimally positioned across the lesions, while two were malpositioned, none obstructing side branch pulmonary arteries. Haemodynamic and angiographic success was attained in 13 procedures, with greater than $50 \%$ increase of vessel diameter. Balloon angioplasty before stenting in eight patients increased vessel diameters from $2.2(0.6) \mathrm{mm}$ to $4.0(1.4) \mathrm{mm}$ $(P<0.005)$. After stent replacement $(n=10$, 17 stents), the mean vessel diameter significantly increased from $2.8(0.9) \mathrm{mm}$ to 5.8 $(1.4) \mathrm{mm} \quad(P \ll 0.001)$. Pressure gradients 


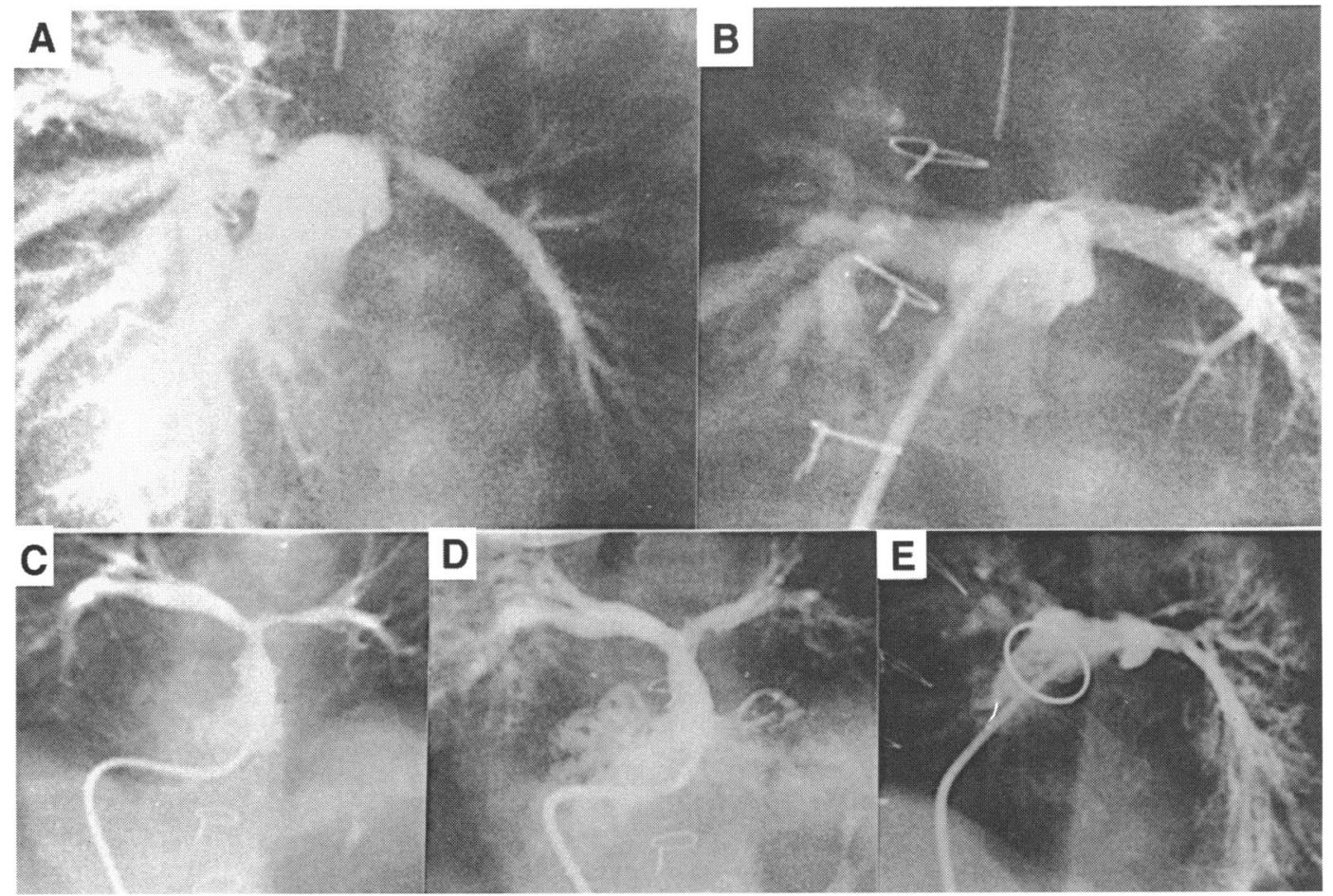

Figure 2 (A) Angiogram of patient 13 with pulmonary artery stenosis showing the congenital hypoplastic bilateral pulmonary arteries. (B) Following the unsuccessful balloon dilatation of the left pulmonary artery, the $15 \mathrm{~mm}$ long stent was expanded to $5.5 \mathrm{~mm}$. (C) In 6 months, the stented left pulmonary artery was narrow. (D) Redilatation of the stent was not effective enough to enlarge the vessel size. (E) After the stent was intraoperatively modified by cutting

longitudinally and augmenting the circumference with a patch, peripheral pulmonary blood flow increased.

declined from a median $40 \mathrm{~mm} \mathrm{Hg}$ to $2 \mathrm{~mm}$ $\mathrm{Hg}(P<0.005, \mathrm{n}=5)$, and right ventricle to systemic artery peak systolic pressure ratio decreased from $0.85(0.19)$ to $0.51(0.12)(P<$ $0 \cdot 005, \mathrm{n}=5)$. Of the 10 patients, clinical success was obtained in eight (11 of 17 stents), four patients with congenital stenoses and the four with acquired stenoses (fig 2). Unsuccessful cases were due to the diffuse hypoplastic nature of the distal pulmonary arteries.

\section{Miscellaneous stenotic vessels}

Nine patients had 12 implants for miscellaneous vascular obstructions (median age 6.5 months, range 14 days to one year). Three patients had stenosis of aortopulmonary anastomoses and one of these had a revised right Blalock-Taussig shunt. Two patients had stenosis of bidirectional cavopulmonary anastomoses, of whom one had a previous stent placed for left pulmonary artery stenosis. Two patients had stenosis of pulmonary veins, one with scimitar syndrome and one after repair of total anomalous venous drainage. The remaining two patients had a superior caval vein obstruction after an arterial repair for transposition of the great arteries or a restrictive atrial septal defect after Blalock-Hanlon procedure.

All patients with aortopulmonary shunts, who had proximal or distal shunt stenoses, recovered adequate pulmonary flow after stent implantation, avoiding repeat palliation. Because of kinking of the shunt after stent implant in one patient, a second stent was placed four months later when the child was over 1 year of age, resulting in improving symptoms (fig 3).

In two patients with obstructive cavopulmonary anastomoses, progressive cyanosis or superior caval syndrome developed. After stent implant, both patients obtained symptom relief. Another patient suffered recurrent superior caval syndrome due to an operational scar after an arterial switch procedure.
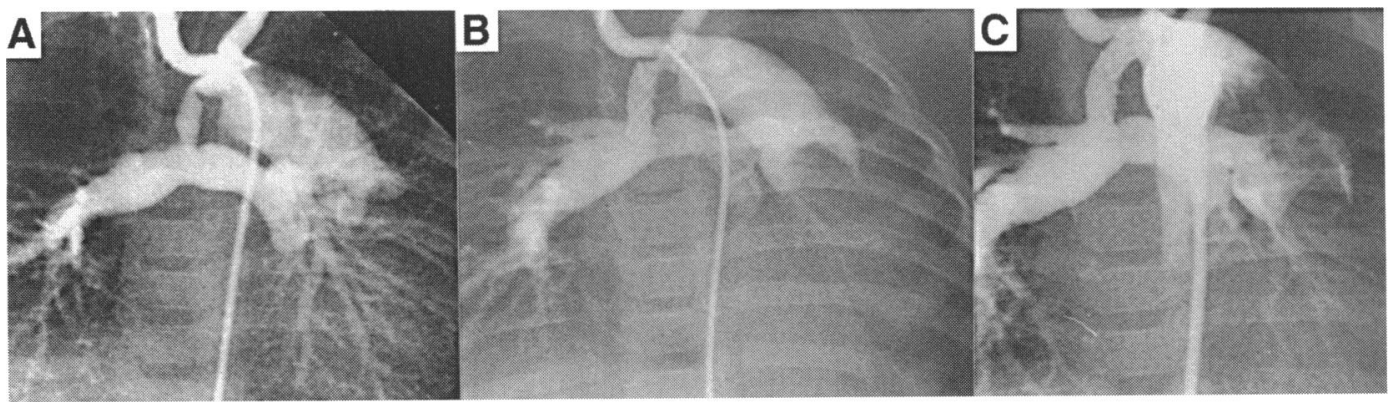

Figure 3 (A) Angiogram of patient 21 with aortopulmonary shunt stenosis showing the proximal and distal narrowings of the subclavian artery. (B) The first $20 \mathrm{~mm}$ long stent was relieving the distal stenosis, but the proximal site remained narrow with over distension. (C) Four months later, with a second $10 \mathrm{~mm}$ long stent placed to overlap the initial device, the whole shunt was patent with an increase in oxygen saturation from $75 \%$ to $85 \%$. 
Balloon angioplasty, including high pressure balloons, was previously unsuccessful, with recoil of the vessel. After stent placement, there was symptom relief and collateral venous flow into the azygos vein disappeared.

In one patient with stenosis of an anomalous pulmonary vein draining to the inferior vena cava with scimitar syndrome, a stent was placed at the junction between the pulmonary vein and inferior caval vein with reduction in pulmonary congestion. Another patient developed bilateral pulmonary vein stenosis four months after repair of total anomalous pulmonary venous drainage, and had intraoperative stent implantation with clinical improvement.

One patient with a restrictive atrial septal defect in the setting of double inlet left ventricle had failed balloon atrial septostomy. Attempted stent implantation to maintain atrial defect diameter by straddling the atria (using an hourglass profile) was not successful because of balloon rupture. The stent was positioned in the superior vena cava and removed the following day at surgery.

\section{COMPLICATIONS}

Complications during implantation occured in seven patients, including stent malpositions ( $\mathrm{n}$ $=5)$, balloon rupture $(n=1)$, and bleeding at a puncture site $(n=1)$. In one patient with conduit stenosis, a deployed stent obstructed the right pulmonary artery blood flow by distorting the ostium of the right pulmonary artery (fig 1). A second patient had a stent positioned just distal to the stenotic lesion in the ductal origin of a left pulmonary artery. Thrombosis of the arterial duct and left pulmonary artery during catheter manipulation resolved with thromolytic therapy, and a central shunt was performed later that day. In a third patient, implantation was first undertaken for left pulmonary artery stenosis, but because of balloon rupture the stent slipped proximally into the right pulmonary artery and was inflated in place. This stent was retieved one month later at surgery. Two stents protruded into aorta or innominate artery in two patients with aortopulmonary shunt (GoreTex) stenosis. Neither obstructed shunt flow or produced thrombus. Balloon rupture in the patient with a restrictive atrial septal defect was mentioned earlier. The patient who bled at a puncture site did not require transfusion.

\section{FOLLOW UP}

Twenty one patients ( $81 \%$ ) have been followed from 24 days to 36 months (median 12 months). No stent has fractured, migrated, or thrombosed. There were 10 patients whose implanted stents were removed or modified at subsequent surgery without technical difficulties, three within one week of implantation (one in each group). The indications for removal were suboptimal placement in six patients, and in four patients, advancement to the next stage of surgical management where the stent was unnecessary. No thrombus was detected in any removed stent. Of these 10 patients, three had the stent modified by cut- ting longitudinally and augmenting the circumference with a patch (fig 2).

Six patients died in this series. There were two early deaths, one during the implant procedure, and another eight days after implantation after pulmonary artery banding (both in the arterial duct group). The four remaining patients died during follow up after further surgical palliation or attempted repair, unrelated to the stent.

\section{RECATHETERISATION AND REDILATATION}

Thirty repeat catheterisations were performed in 19 patients $(73 \%)$ with a median period of eight months (range 12 days to 28 months) after implantation. There were no side branch stenoses in the group with pulmonary artery implants. Of the two patients with stenotic pulmonary veins, one (with scimitar syndrome) developed total occlusion of the stent noted at the 11 months follow up, but remained asymptomatic. Another patient (with postoperative total anomalous pulmonary venous drainage) developed restenosis of all the implants and required a second intraoperative redilatation of the veins with additional stent placement at four months and $2 \cdot 3$ years after implantation.

Eleven patients $(42 \%)$ had redilatation of 17 stents (14 procedures) within a median 10 months (range three to 22 months) after implantation. Redilatation was attempted because of restenosis of the stent associated with clinical symptoms, or the necessity for improvement in peripheral pulmonary artery flow to encourage growth with small distal pulmonary arteries. Of the 11 patients, a successful haemodynamic response was attained each in three of four conduits, one of six pulmonary artery stenoses, and one cavopulmonary artery stenosis, (table 2, patient 24 had redilatation at different stenotic sites). An attempt to dilate the stent in the patient with total anomalous pulmonary venous drainage was unsuccessful. In responders, intimal proliferation was absent in one patient, mild in three, and moderate in one. In non-responders, intimal proliferation was absent in three patients, moderate in one, and severe in three, but distal vessel hypoplasia was a prominent feature in five patients (fig 2). In those with conduit stenosis (three responders), the right ventricle to systemic artery peak systolic pressure ratio decreased from $0.64(0.04)$ to 0.43 $(0.02)(P<0.005)$.

\section{Discussion}

This review supports previously reported experiences in older children, that endovascular stent implantation is safe and effective acutely in a variety of stenotic lesions, even when used in children less than 1 year of age. There were no technical difficulties in stent delivery with either percutaneous or intraoperative implantation. The initial experience of O'Laughlin et $a l^{4}$ suggested that the most favourable candidates were in the older population; however, in their series, mean age was 13.1 years. In another report, 
Mendelsohn and colleagues ${ }^{3}$ had only three infants (of 16) with intraoperative implantations. Our larger experience suggests that age per se is not necessarily a limiting factor in stent use, but they should be used only under certain qualified circumstances.

Stent malposition or embolisation is a serious complication. ${ }^{24}$ In our series, six stents were placed improperly, although in two this resulted in no adverse effects and the malposed stents were successfully removed during later surgery without difficulty. Our experience suggests that stents can compromise pulmonary blood flow or create an obstacle to contralateral access when placed within the smaller and more confined area of the pulmonary outflow in small children, although this is not considered unique to younger patients. A larger selection of stent lengths may address this issue. These implants will result in intrinsic obstruction with patient growth and with the development of intimal hyperplasia. Repeat stent dilatation adjusted to vessel growth will be necessary and this limits the usefulness of the smaller implants possible in infants. In this regard, large diameter stents (iliac size), however, are not technically feasible for implantation in the smallest of children.

Our patients experienced significant clinical improvement both acutely and in the short term. The multiplicity of vascular lesion, however, requires individual assessment. In the setting of a restrictive arterial duct, earlier reports indicated that stenting could afford palliation for duct dependent congenital heart lesion. ${ }^{8-10}$ Our experience is consistent with these observations. Infants with conduit implantations will require further replacement with somatic growth or acquired conduit stenosis. ${ }^{11-13}$ In our patient series, conduit stenosis developed after a median period of 6.6 months. In attempt to avoid early reoperation, balloon dilatation has been employed with mixed results. ${ }^{14}{ }^{15}$ Stenting, on the other hand, appears more reliable in achieving an increase in conduit diameter and has previously been reported to improve acute haemodynamics. $^{2}$ In our patients with conduit obstruction after unsuccessful balloon angioplasty, stenting was used as an alternative to reoperation. Except for the one patient requiring reoperation, the stent obstructing the right pulmonary artery, four were haemodynamically and anatomically successful, avoiding surgical reintervention and suggesting that stenting for conduit stenosis may be an alternative to reoperation in even younger children. In pulmonary artery stenosis, most studies have supported stent implantation as an effective procedure in enlarging vessel lumens after unsuccessful balloon angioplasty. ${ }^{2-4}$ In this regard, clinical success was achieved in $60 \%$, resulting in improved haemodynamics and a positive impact on the patient's clinical course. Again, caution must be raised in such applications, as the acute haemodynamic and clinical improvements must be tempered by long term concerns over distal pulmonary artery growth. Thus, in this age group, distal implants are discouraged and only main pulmonary branch vessels should be addressed. Thereafter, if further surgery is anticipated, stent modification can be performed. The patients with miscellaneous vascular lesions showed clinical improvement and had the highest success rate $(80 \%)$. However, stenting was unsuccessful in pulmonary vein stenosis because of rapid reocclusion and tissue ingrowth.

Restenosis of the stent is one of greatest concern in follow up. O'Laughlin et $a l^{4}$ reported only one patient (of 58) with haemodynamic or angiographic evidence of restenosis, although most of the stents had some degree of intimal proliferation. In our study, significant restenosis with severe intimal proliferation was found in three patients. While recent reports indicate that stent redilatation is possible without adverse effects, ${ }^{416}$ our data show that the patients most likely to respond were those whose intimal overgrowth was absent or only of a mild degree. Additionally noted was that most non-responders had associated diffuse hypoplasia of the distal pulmonary vessels, regardless of the degree of intimal proliferation. This may have resulted from either an intrinsic abnormality within the pulmonary tree or a secondary effect upon growth of the implanted stent. While acutely relieving the obstruction, rapid intimal proliferation may reduce ipsilateral pulmonary blood flow and result in a hypoplastic vessel distal to the stent. This may produce further patient compromise and limit of the effectiveness of the technique.

In conclusion, we suggest from this experience that stent implantation is technically feasible for infants with a variety of obstructive vascular lesions and provides acute clinical improvement. It can be used as an alternative to surgical palliation or to avoid reoperation. Redilatation of the implant is possible for restenosis; however, in the setting of diffuse hypoplasia of the pulmonary arteries, the improvement is minimal. Long term effects of such small stents may, however, be ultimately detrimental.

1 O'Laughlin MP, Perry SB, Lock JE, Mullins CE. Use of endovascular stents in congenital heart disease. Circulation 1991;83:1923-39.

2 Hosking MCK, Benson LN, Nakanishi T, Burrows PE, Williams WG, Freedom RM, et al. Intravascular stent prosthesis for right ventricular outflow obstruction. $\mathcal{F} \mathrm{Am}$ prosthesis for right ventricula

3 Mendelsohn AM, Bove EL, Lupinetti FM, Crowley DG, Lloyd TR, Fedderley RT, et al. Intraoperative and perLloyd TR, Fedderley RT, et al. Intraoperative and percutaneous stenting of congenital pulmonary artery and
vein stenosis. Circulation 1993;88(suppl II):II-210-7.

4 O'Laughlin MP, Slack MC, Grifka RG, Perry SB, Lock JE, Mullins CE. Implantation and intermediate-term follow-up of stents in congenital heart disease. Circulation 1993;88:605-14.

5 Benson LN, Hamilton F, Dasmahapatra H, Rabinowitch M, Coles JC, Freedom RM. Percutaneous implantation of a balloon-expandable endoprosthesis for pulmonary artery stenosis: an experimental study. $\mathcal{F} \mathrm{Am}$ Coll Cardiol 1991;18:1303-8.

6 Rothman A, Perry SB, Keane JF, Lock JE. Early results and follow-up of balloon angioplasty for branch pulmonary artery stenosis. $\mathcal{F}$ Am Coll Cardiol 1990;15: 1109-17.

7 Hosking MCK, Thomaidis C, Hamilton R, Burrows PE, Freedom RM, Benson LN. Clinical impact of balloon angioplasty for branch pulmonary arterial stenosis. $A m \mathcal{F}$ Cardiol 1992;69:1467-70. 
8 Gibbs IL, Rothman MT, Rees MR, Parsons JM, Blackburn ME, Ruiz CE. Stenting of arterial duct: a new approach to palliation for pulmonary atresia. Br Heart $\mathcal{f}$ approach to pal

9 Ruiz CE, Gamra H, Zhang HP, Garcia EJ, Boucek MM Brief report: stenting of the ductus arteriosus as a bridge to cardiac transplantation in infants with the hypoplastic left-heart syndrome. $N$ Engl $f$ Med 1993;328 1605-8.

10 Rosenthal E, Qureshi S, Tynan M. Percutaneous pulmonary valvotomy and arterial duct stenting in neonates with right ventricular hypoplasia. Am F Cardiol 1994 74:304-6.

11 Jonas RA, Freed MO, Mayer JE, Castaneda AR. Longterm follow-up of patients with synthetic right heart conduits. Circulation 1985;72(suppl II):II-77-83.

12 McGoon DC, Danielson GK, Puga FT, Ritter DG, Mair
DD, Ilstrup DM. Late results after extracardiac conduit repair for congenital cardiac defects. Am $\mathcal{f}$ Cardiol 1982; 49:1741-9.

13 Razzouk AJ, Williams WG, Cleveland DC, et al. Surgical connections from ventricle to pulmonary artery: comparison of four types of valved implants. Circulation 1992;86(suppl II):II-154-8.

14 Zeevi B, Keane JF, Perry SB, Lock JE. Balloon dilation of postoperative right ventricular outflow obstruction. $\mathcal{f} \mathrm{Am}$ Coll Cardiol 1989;14:401-8.

15 Ensing GJ, Hagler DJ, Seward JB, Julsrud PR, Mair DD Caveats of balloon dilation of conduits and conduit valves. F Am Coll Cardiol 1989;14:367-400.

16 Morrow WR, Palmaz JC, Tio FO, Ehler WJ, VanDellen AF, Mullins CE. Re-expansion of balloon-expandable stents after growth $\mathscr{f} A m$ Coll Cardiol 1993;22: 2007-13.

\section{IMAGES IN CARDIOLOGY}

\section{Extreme pulsus alternans presenting as 2:1 electromechanical dissociation}

A 12 year old boy presented with pulmonary oedema and severe hypertension and was found to be in end stage renal failure. The echocardiogram showed a dilated but well contracting left ventricle with mild hypertrophy. He was ventilated for 24 hours, but after haemodilalysis was started he was able to be extubated and became ambulant. During his fourth dialysis cycle, 5 days after admission, he became dizzy, hypotensive, and bradycardic. Auscultation and an electrocardiographic monitoring lead revealed a heart rate that was double his pulse rate. The echocardiogram showed that the aortic valve only opened every second electrocardiographic complex (left panel b) and a Doppler signal in the descending aorta was only present every second electrocardiographic complex (left panel c). Ventricular function was considerably depressed and an $M$ mode tracing showed alternate strong and weak contractions (arrows) (left panel a). The mitral, tricuspid, and pulmonary valves opened with every electrocardiographic complex. Serum calcium was $1.55 \mathrm{mmol} / \mathrm{l}$. After calcium was replaced and an infusion of dobutamine (5 $\mu \mathrm{g} / \mathrm{kg} / \mathrm{min}$ ) was started he initially developed palpable pulsus alternans (middle panel $a, b, c)$ and then full pulses (right panel $a, b, c)$.

ERIC ROSENTHAL
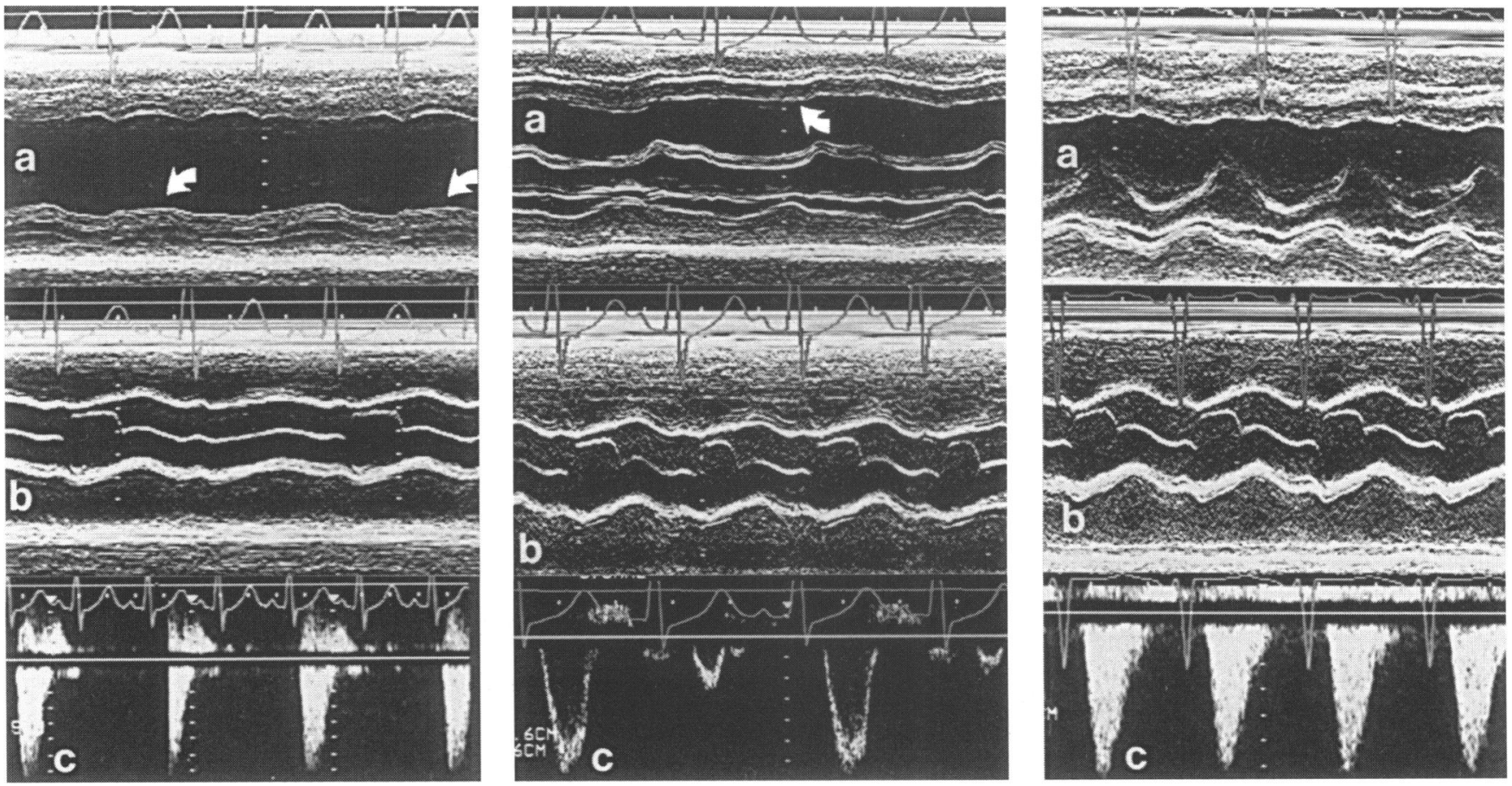

In all three panels (left, middle, right) $a$ is an $M$ mode tracing of left ventricle, $b$ is an $M$ mode tracing of aortic valve, and $c$ is a Doppler tracing from the descending aorta. All traces are at the same paper speed except for the left panel $c$ which is at half speed. Time markers are $0 \cdot 2 \mathrm{~s}$. Depth markers are $1 \mathrm{~cm}$ in $a$ and $b$ and $20 \mathrm{~cm} / \mathrm{s}$ in $c$. 